\title{
A Arte de Envelhecer: Um Estudo Exploratório Sobre a História de Vida e o Envelhecimento
}

The Art of Aging: An Exploratory Study on Life History and Aging

El Arte de Envejecer: Un Estudio Exploratorio Sobre la Historia de Vida y el Envejecimiento
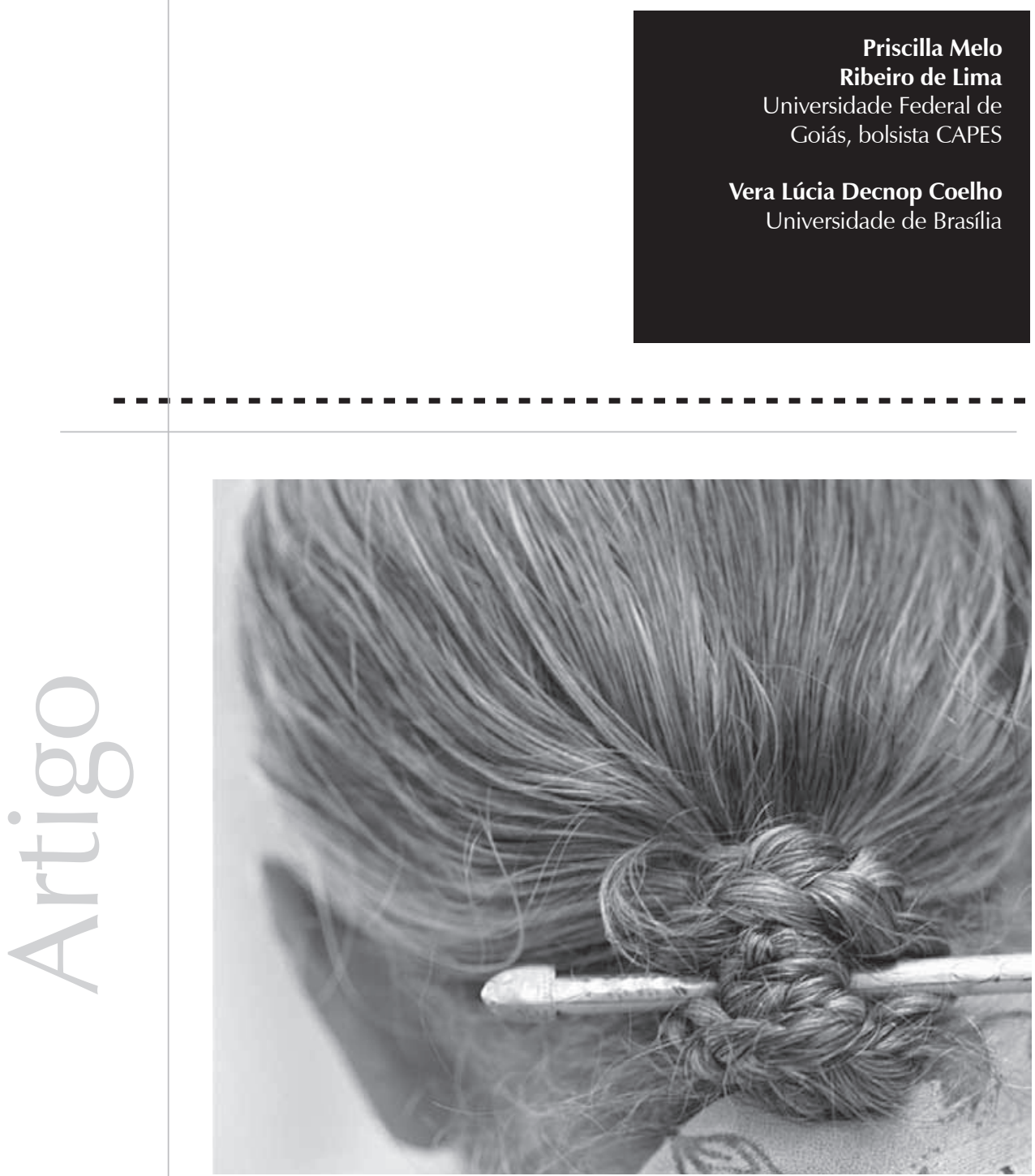
Resumo: O presente estudo objetivou, a partir da teoria epigenética do ciclo de vida e da perspectiva do desenvolvimento ao longo da vida, (1) conhecer aspectos do envelhecimento à luz da história de vida de oito idosos, (2) investigar o modo como estratégias de seleção, otimização e compensação e envolvimento vital se manifestam e (3) explorar contribuições da geratividade e da participação social no processo de envelhecer de oito idosos. Os idosos participaram de entrevista semiestruturada. A análise dos dados revela que fatores como participação social, geratividade e relacionamento com filhos e netos influenciam a construção de um envelhecimento bem-sucedido. Por outro lado, fatores como estagnação e ausência de envolvimento social parecem contribuir para o aparecimento de sintomas psicopatológicos.

Palavras-chave: Desenvolvimento psicossocial. Envolvimento social. Geratividade.Envelhecimento.

Abstract: The present study, based on the life cycle epigenetic model and lifespan psychology, was designed to (1) understand aspects of the aging process from eight elders' life stories, (2) investigate the way selective optimization with compensation strategies and vital involvement aspects appear in old age as well as (3) the contributions of generativity and social participation to the aging process. The subjects participated in a semi-structured interview. A qualitative analysis of the data pointed out the influence of several factors on the construction of a successful aging such as generativity, social participation and relationship with their children and grandchildren. Factors such as stagnation and lack of social involvement seem to contribute to the development of psychopathology symptoms.

Keywords: Psychosocial development. Social involvement. Generativity. Aging.

Resumen: El presente estudio objetivó, a partir de la teoría epigenética del ciclo de vida y de la perspectiva del desarrollo a lo largo de la vida, (1) conocer aspectos del envejecimiento a la luz de la historia de vida de ocho personas de edad, (2) investigar el modo como estrategias de selección, optimización y compensación e involucración vital se manifiestan y (3) explotar contribuciones de la generatividad y de la participación social en el proceso de envejecer de ocho personas de edad. Estas personas de edad participaron de entrevistas semi-estructuradas. El análisis de los datos revela que factores como participación social, generatividad y relacionamiento con hijos y nietos influencian la construcción de un envejecimiento bien llevado. Por otro lado, factores como estancamiento y ausencia de envolvimiento social parecen contribuir para el aparecimiento de síntomas psicopatológicos.

Palabras clave: Desarrollo psicosocial. Participación parental. Generatividad. Envejecimiento.

Pesquisas nos campos da Psicologia do desenvolvimento e da gerontologia têm demonstrado que o fenômeno do envelhecimento é complexo e envolve vários fatores que se entrelaçam no decorrer da vida (An \& Cooney, 2006; Baltes \& Baltes, 1990; Erikson, 1950/1963, 1982/1998, 1986; Neri \& Yassuda, 2004; Tornstam, 1999). Sobretudo os estudos de Baltes e Baltes (1990) e Erikson (1986, 1982/1998) demonstram que o desenvolvimento humano é multidirecional, multidimensional e dinâmico, balanceando ganhos e perdas. Assim, não são apenas os aspectos da atualidade do idoso, como boa saúde física e mental, que caracterizam a velhice como bem-sucedida, pois esta necessita ser construída durante todo o ciclo de vida. O estudo aqui apresentado buscou explorar a influência de alguns fatores na construção do envelhecimento de oito idosos: estratégias de seleção, otimização e compensação, geratividade e envolvimento social. Dentre as propostas teóricas da Psicologia do desenvolvimento que estudam esses fenômenos, destacaremos o modelo epigenético do ciclo de vida e a perspectiva do desenvolvimento ao longo da vida (Lifespan Psychology).

\section{O modelo epigenético do ciclo de vida}

Esse modelo entende o desenvolvimento humano a partir de fases sucessivas com tarefas específicas a serem realizadas. De acordo com Erikson (1982/1998), cada fase é assinalada por um balanço dinâmico entre um componente sintônico - que busca o equilíbrio interno - e um distônico - caracterizado pela desarmonia. Denominou-se crise à tensão dinâmica entre esses componentes, cuja resolução objetiva a conquista de uma força psicossocial. A fim de superar cada crise, o sujeito precisa experimentar 
Joan Erikson (1998)

afirma que as virtudes adquiridas ao longo do desenvolvimento são desafiadas ao final da vida, principalmente na nona etapa, pelo declínio das habilidades físicas e mentais. a sintonia e a distonia. O êxito da sintonia dependerá do contexto e das relações sociais além da capacidade interna em vencer as próprias limitações. As fases propostas por Erikson $(1950 / 1963 ; 1982 / 1998)$ e as forças psicossociais a serem adquiridas são: $\left(1^{\mathrm{a}}\right)$ confiança versus desconfiança: esperança; (2) autonomia versus vergonha: força de vontade; $\left(3^{\text {a }}\right)$ iniciativa versus culpa: propósito; $\left(4^{a}\right)$ realização versus inferioridade: competência; $\left(5^{\text {a }}\right.$ ) identidade versus confusão de papéis: fidelidade; $\left(6^{\mathrm{a}}\right)$ intimidade versus isolamento: amor; $\left(7^{\mathrm{a}}\right)$ geratividade versus estagnação: cuidado; $\left(8^{a}\right)$ integridade versus desespero: sabedoria; $\left(9^{\mathrm{a}}\right)$ ressurgimento das crises anteriores: gerotranscendência.

Durante todo o ciclo vital, o indivíduo é desafiado a estabelecer novas relações consigo e com o mundo e a superar limitações. Cada estágio envolve o indivíduo em um processo de reintegração dos temas psicossociais experimentados em estágios precedentes a novos temas relacionados à idade (Erikson, Erikson, \& Kivnick, 1986; Wadensten, 2006). Os principais desafios associados à oitava e à nona etapas são resolver conflitos do passado, investir nas relações sociais do presente e encarar a finitude da vida com serenidade. Assim, a aquisição da virtude sabedoria corresponde à capacidade de equilibrar um sentido de coerência e plenitude pessoal com o desespero perante a proximidade da morte, além da aceitação das falhas e omissões do passado. Nessa perspectiva, o elemento sintônico do sétimo estágio, a geratividade, é um aliado na luta contra o desespero. Esse fenômeno envolve a capacidade e a necessidade produtiva inerente a todo ser humano, abrange a geração e o cuidado com os filhos e desafia o sujeito a se comprometer com múltiplas esferas sociais, exercer função de liderança e orientação na relação com filhos e netos, além de auxiliá-los a desenvolver confiança, autonomia, iniciativa e identidade (Bradley \& Marcia, 1998). É a geratividade que suscita o envolvimento vital no idoso e o auxilia a sentir-se vivo e a manter ativas suas relações sociais. Erikson, Erikson, e Kivnick (1986) afirmam que essa capacidade de envolvimento habilita o indivíduo a estabelecer relações recíprocas com o meio social, e precisa ser sempre estimulada.

$\mathrm{Na}$ velhice, com o aumento da força do elemento distônico desespero e a contínua sensação de estagnação, ou seja, de ausência de propósito, a necessidade de vínculos sociais torna-se mais evidente. Compartilhar da vida dos filhos e netos, ensinar e deixar algo para as próximas gerações e manter relações sociais pode gerar e aumentar o envolvimento vital. Muitas vezes fisicamente limitado e confrontado com a finitude da vida, o idoso se encontra lutando para aceitar a inalterabilidade do passado e a incognoscibilidade do futuro, reconhecer erros e omissões e balancear o consequente desespero com o senso de integridade que é essencial para continuar vivendo (Erikson, Erikson, \& Kivnick, 1986).

Joan Erikson (1998) afirma que as virtudes adquiridas ao longo do desenvolvimento são desafiadas ao final da vida, principalmente na nona etapa, pelo declínio das habilidades físicas e mentais. O idoso que tiver superado anteriormente as crises e estiver inserido em um contexto psicossocial que o auxilie na superação das dificuldades dessa etapa não permitirá que o desespero tome conta de sua existência. Dessa forma, tenderá a encarar a finitude da vida com serenidade e sabedoria, experimentará envolvimento vital e, possivelmente, adquirirá a virtude da gerotranscendência (Yount, 2009). Esta envolve transcender as limitações corporais, experimentar nova compreensão do tempo, de si mesmo e das relações sociais, sensação de conexão com as gerações anteriores e nova compreensão da vida e da morte (Erikson, 1998).

No outro extremo, temos o elemento distônico do desespero, que se contrapõe à integridade. Esse elemento é experimentado quando o idoso, ao olhar sua trajetória, 
vislumbra sua existência através dos erros cometidos. A vida, sob o olhar do desespero, é vista como um conjunto de tarefas não terminadas, falhas e limitações. Yount sustenta que o idoso em desespero "abriga ressentimentos acerca da brevidade da vida e do fato de que não pode começar tudo de novo" (2009, p.79). O sujeito, portanto, é incapaz de integrar experiências positivas e negativas, erros e acertos, em uma perspectiva ampla da vida. Muitas vezes, esse idoso acaba por desenvolver psicopatologias como fuga ante o desgosto de viver (Birman, 1995; Goldfarb, 2004).

Cada crise surge em resposta a uma demanda psíquica e a uma demanda psicossocial. Assim, Erikson faz um entrelaçamento dos mundos interior e exterior do indivíduo e de suas influências em cada etapa do desenvolvimento. Nas duas últimas etapas, o ambiente social se faz ainda mais preponderante no auxílio à superação da distonia. Erikson ressalta que "a falta de um ideal culturalmente viável da velhice faz com que nossa civilização não tenha realmente onde ancorar um conceito de totalidade da vida" (1982/1998 p. 114). Na medida em que a sociedade não consegue valorizar o idoso e proporcionar-lhe ambiente saudável e motivador, ter um senso de completude e de totalidade da vida se torna mais difícil.

A perspectiva da Psicologia do desenvolvimento ao longo da vida (Lifespan Psychology), desenvolvida por Paul Baltes e colaboradores (1987), também concebe o desenvolvimento humano como um processo contínuo, com seus ganhos e perdas em todas as etapas, como veremos a seguir.

\section{Perspectiva do desenvolvimento ao longo da vida (Lifespan Psychology)}

Essa perspectiva compreende o desenvolvimento a partir do indivíduo e do que é comum aos membros de determinada sociedade. Dessa forma, concebem-se três influências que atuam sobre o sujeito durante seu ciclo vital: (1) influências normativas ontogenéticas, ou seja, eventos que ocorrem de forma relativamente homogênea entre os sujeitos, p. ex., infância, adolescência, menopausa, etc; (2) influências normativas históricas, que envolvem acontecimentos macroestruturais que originam mudanças biossociais, como é o caso de guerras, crises econômicas, novas tecnologias, etc., e (3) influências não normativas, que podem ter caráter biológico ou societário e são imprevisíveis, como doença grave, luto, ganhar na loteria, etc. Esses fatores estão continuamente compelindo o indivíduo e seu ambiente a se adaptarem. O sujeito é, então, constantemente requisitado a buscar equilíbrio entre limitações e potencialidades. O êxito desse balanceamento é o que caracterizaria o desenvolvimento bemsucedido (Baltes, 1987).

A partir dessa concepção e com o foco na plasticidade comportamental, Baltes e Baltes (1990) propuseram um modelo adaptativo composto de estratégias de seleção, otimização e compensação (SOC). Essas estratégias são utilizadas pelo indivíduo com o objetivo de manejar satisfatoriamente mudanças biológicas, psicológicas e sociais e propiciam oportunidades e limitações (Neri, 2006a). Objetivando um desenvolvimento bem-sucedido, a seleção abrange a busca por melhor funcionamento psíquico ante novos desafios, como o aprendizado de novos comportamentos, englobando a minimização das perdas de determinadas capacidades. Isso ocorre na velhice, por exemplo, quando o sujeito buscará amenizar perdas físicas e desenvolver novas habilidades. É uma tarefa adaptativa que abrange demandas ambientais e motivações e capacidades individuais. A otimização inclui a aquisição ou a articulação de meios, internos ou externos, para viabilizar a conquista dos alvos estabelecidos pela seleção. O indivíduo poderá utilizar recursos 
Uma habilidade resultante do uso das estratégias de SOC ao longo da vida é a sabedoria. Na psicologia do Lifespan, essa virtude é concebida como o resultado da articulação de componentes cognitivos e sociais que visam a converter situações negativas em positivas; seria uma aptidão pessoal e social utilizada para negociar mudanças e desafios da vida, objetivando viver uma boa vida e buscar o bem comum (Glück, Bluck, Baron, \& McAdams, 2005). educacionais e sociais visando a sua saúde e a habilidades sociais, como a participação em associação de idosos. A compensação compreende uma reação à perda de certas aptidões e envolve buscar novas maneiras de manter ou melhorar habilidades. Assim, ao enfrentar, por exemplo, dificuldades de memorização, o indivíduo pode utilizar-se de bilhetes em lugares estratégicos para se lembrar.

Os resultados esperados ao final da SOC são: a maximização de ganhos, a regulação e a minimização de perdas e a manutenção de funções adquiridas, incluindo a resiliência. Essas estratégias são utilizadas a cada mudança no curso de vida, em decorrência de influências normativas graduadas pela idade, pela história ou não normativas. A forma de utilizar esses instrumentos de adaptação depende de fatores pessoais e sociais. Atividades educacionais e motivacionais promovidas pela comunidade, como as universidades abertas, contribuem para que idosos possam lançar mão dessas estratégias adaptativas de forma eficaz (Baltes \& Baltes, 1990).

Uma habilidade resultante do uso das estratégias de SOC ao longo da vida é a sabedoria. Na psicologia do Lifespan, essa virtude é concebida como o resultado da articulação de componentes cognitivos e sociais que visam a converter situações negativas em positivas; seria uma aptidão pessoal e social utilizada para negociar mudanças e desafios da vida, objetivando viver uma boa vida e buscar o bem comum (Glück, Bluck, Baron, \& McAdams, 2005). Apesar de estar comumente associada à velhice, a sabedoria é uma capacidade construída durante a vida.

O processo de envelhecimento biológico pressupõe redução da plasticidade comportamental e da resiliência biológica. Esses fatores estão intrinsecamente ligados às condições histórico-culturais, ao apoio social e aos recursos da personalidade presentes ao longo da vida. Se estiverem presentes, mesmo frente às perdas da velhice, o idoso poderá desfrutar de continuidade em seu funcionamento psicossocial e de bem-estar na velhice (Neri, 2006b). Assim, o envelhecimento bem-sucedido pode ser apreendido como uma competência adaptativa de responder aos desafios emergentes a partir do corpo, mente e ambiente com resiliência (Featherman, Smith, \& Peterson, 1990).

\section{Pontos e contrapontos}

Não obstante enfocarem aspectos diferentes do desenvolvimento humano, pois Erikson (1950/1963; 1982/1998; 1986) investigou o desenvolvimento do ego e Baltes (1987; 1990; 1997), os aspectos cognitivos e adaptativos do indivíduo, tentaremos articular algumas questões que possam contribuir para a compreensão da velhice. Ambas as perspectivas enfocam a importância do contexto social no enfrentamento das perdas e na busca por novas possibilidades de superá-las. É inegável a influência do ambiente na construção da identidade e na promoção de estratégias adaptativas que auxiliem na superação de desafios inerentes à condição humana.

Baltes e Baltes, (1990) ressaltam a importância de um engajamento pessoal por estilo de vida saudável a fim de reduzir a probabilidade de condições patológicas na velhice. $\mathrm{O}$ fortalecimento das capacidades cognitivas dos indivíduos através da educação, a motivação e as atividades relacionadas à saúde, além da formação e da manutenção de redes sociais de apoio são importantes para uma velhice bem-sucedida. Devido à diminuição de sua capacidade adaptativa, pessoas idosas terão especial necessidade de apoios compensatórios; destarte, ambientes favoráveis que tragam melhorias nas 
condições desenvolvimentais e que exijam menos da capacidade cognitiva do idoso são imprescindíveis para uma boa velhice. A mudança no equilíbrio entre ganhos e perdas sugere levar-se em consideração a busca de estratégias para facilitar o ajuste do idoso à realidade. A grande questão será auxiliar o velho na aquisição de estratégias adaptativas que envolvam mudanças em aspirações e projetos e que se adequem às suas novas demandas. Dessa forma, a abordagem baltesiana reflete uma visão voltada para a pragmática da vida atual do indivíduo.

Erikson (1982/1998) enfatiza igualmente a importância de ambiente social favorável ao idoso e às suas necessidades. Enquanto Baltes $(1987 ; 1990 ; 1997)$ realça o auxílio ambiental na construção de estratégias para o enfrentamento de perdas, Erikson (1982/1998; 1986) possui um caráter mais reflexivo acerca da vida e da velhice. Esse autor destaca a necessidade de olhar para dentro de si, das relações sociais e da geratividade na construção do envolvimento vital.

A crise da sétima etapa - geratividade e estagnação - permanece presente na velhice e exige do indivíduo a revisão de seus próprios anos de responsabilidade ativa na criação dos filhos, além da retomada de experiências de cuidado em relação à geração de seus pais. Assim, a frustração e o arrependimento pelo abandono de projetos de estudos e carreira em função do casamento e dos filhos muitas vezes são substituídos pelo orgulho em ver as conquistas dos próprios filhos e netos. Alguns idosos conseguem, após a aposentadoria e a saída dos filhos de casa, reinvestir em projetos devidamente adaptados à fase atual da vida. O relacionamento com os netos pode oferecer ao idoso nova oportunidade de geratividade e cuidado e possibilidade de ser lembrado após a morte (Erikson Erikson, \& Kivnick, 1986). Tornstam (1999) afirma que o vislumbre de dar algo à posteridade e de sentir-se integrante da dimensão histórica da vida é uma forma de enfrentar o desespero ante a finitude.

Respeitando-se as peculiaridades de cada teoria, ambas oferecem subsídios importantes para se avaliar a velhice. Dessa forma, utilizaram-se no presente estudo os pressupostos do envolvimento vital e das estratégias de SOC, além dos conceitos de sabedoria, objetivando: 1. conhecer aspectos do processo de envelhecimento à luz da história de vida de oito idosos; 2 . investigar como se dá o envolvimento vital e o processo de SOC durante a trajetória de vida e no presente desses idosos; 3. investigar as contribuições da geratividade e da participação social na construção do envelhecimento.

\section{Método}

\section{Participantes}

Participaram do estudo oito idosos, sendo cinco mulheres e três homens entre 68 e 81 anos. A amostra foi de conveniência (Moura \& Ferreira, 2005), formada por quatro pacientes do Centro de Medicina do Idoso (CMI) da Universidade de Brasília e por quatro residentes em Anápolis. Na tentativa de conhecer a experiência de idosos que estavam inseridos em um contexto hospitalar, optou-se por selecionar indivíduos pacientes de um centro de assistência multidisciplinar a idosos da rede pública de saúde. Objetivando conhecer aspectos da experiência de vida e de envelhecer em idosos da comunidade, foram selecionados participantes moradores de Anápolis e membros de uma igreja que oferece atividades sociais. O objetivo do estudo não era comparar os grupos, mas investigar os aspectos do envelhecimento de cada sujeito. 


\section{Instrumentos, procedimentos e análise de dados}

Foi realizada entrevista semiestruturada, com ênfase na história de vida do idoso, cujos tópicos abordaram: eventos marcantes na vida pregressa e atual, vida social, história ocupacional, relações familiares e conquistas e perdas passadas e presentes. O projeto foi aprovado pelo Comitê de Ética em Pesquisa da Faculdade de Medicina da Universidade de Brasília. As entrevistas foram gravadas com a permissão dos participantes e analisadas a partir de uma análise qualitativa. O método utilizado foi o estudo de caso devido às peculiaridades de cada história, e teve o intuito de preservar o caráter unitário dos relatos (Minayo, 2007). A síntese das histórias procurou identificar: geratividade e estagnação, participação social, estratégias de SOC, integridade e desespero ante a finitude da vida e sabedoria. As informações pessoais e os nomes dos sujeitos foram alterados. Os primeiros quatro sujeitos são pacientes do CMI, e os demais, moradores de Anápolis.

\section{Resultados}

\section{Geraldo: a arte de vislumbrar um futuro possível}

Geraldo tem 75 anos, é casado há 42 anos e tem 3 filhas. Nasceu no interior de Minas Gerais e mudou-se para a capital para terminar o ensino fundamental. Após a conclusão do ensino médio, cursou Sociologia. Aposentou-se como professor universitário, mas continuou a trabalhar como sociólogo e articulista de alguns sites de Sociologia e política quando sofreu um acidente vascular cerebral (AVC) aos 73 anos. A partir de então, sua vida mudou. Apresenta dificuldades para caminhar, para articular palavras e enxergar. Durante a entrevista, sua fala deixou transparecer certo desapontamento com a vida: "Eu podia estar com mais saúde. Pelo tipo de vida que levo, não fiz tanto estrago assim pra merecer esse AVC e estar com essas limitações. Era muito serelepe, não tomava remédio nenhum". Esse fato parece trazer-lhe um questionamento sobre o presente e talvez uma confusão de identidade ao se deparar com uma nova situação em seu ciclo vital. O presente parece ainda indefinido, um interlúdio entre o que foi e o que será: "Mas não me considerava velho não, me achava garoto maduro, e, com o AVC, fiquei velho de uma noite... pro amanhã... me alertou que eu não tinha mais 17 anos". Para quem sempre gozou de boa saúde, trabalhou com disposição grande parte da vida, e se via como um garotão parece estar sendo difícil reconhecer-se velho. Embora tenha parado de trabalhar, Geraldo utiliza a internet para manter-se produtivo, escrever e publicar artigos, entrar em contato com amigos e escritores. A produtividade intelectual e o trabalho são aspectos marcantes em sua vida.

Uma das sequelas do AVC é a dificuldade em enxergar. Os olhos são seus instrumentos de trabalho e se relacionam com atividades que aprecia: ler e escrever. Diante disso, a intervenção cirúrgica à qual foi submetido parece trazer-lhe alento e vislumbre de possibilidade de futuro e adiamento da morte: "Tá parecendo agora que fiz operação de vista, que posso ter tempo ainda pra terminar meu livro". O assunto tratado pelo livro é segundo Geraldo, a relação do homem com a natureza e como será o futuro da humanidade e a vida das gerações futuras.

O tema família também é presente no depoimento de Geraldo, que demonstra orgulho do seu casamento e das filhas, e de ter Ihes dado a melhor educação possível. Sua participação social atual envolve, sobretudo, eventos familiares. Relata que, quando jovem, era muito farrista, tocava violão e fazia serenatas. Mas, atualmente, afirma não ter hábito de sair. 
Luíza e a elaboração do luto pelos sonhos não realizados

Luíza tem 74 anos, é casada há 51 anos e tem 4 filhos. Nasceu e viveu no Rio de Janeiro até os 8 anos, quando a família decidiu se mudar para Goiás. Moraram durante algum tempo no interior, mudando-se para a capital quando Luíza tinha 10 anos, e lá fez o ensino médio em contabilidade. Afirma que precisava trabalhar durante o dia para conseguir pagar os estudos e ajudar em casa. Após o ensino médio, começou a trabalhar. Ao se casar, largou o emprego: "Naquela época, quando casava tinha que sair do trabalho... foi bobagem minha. A gente quer viver ao lado do marido, arrumando casa feito uma Amélia. Foi tudo errado". Declara que sempre abriu mão de sonhos em função do trabalho do marido e imputa a este a responsabilidade pelo que não conquistou: "Não fiz faculdade porque morava sempre em lugar ruim e pequeno por causa dele, e não parava muito tempo, era três, cinco, dois anos. Pra mim foi sofrido, eu achei um pouco difícil".

A falta de estudos parece ter impossibilitado a melhoria de vida ao se mudar para Brasília quando o marido deixou de trabalhar em uma instituição, chamada genericamente de missão, que treina voluntários para implantar igrejas. Ao relatar esse momento, mostra contrariedade, mas, ao mesmo tempo, demonstra orgulho pela disposição que teve para o trabalho. Como consequência, buscou realização nas conquistas dos filhos: "Agora joguei para os filhos aquela vontade (de cursar uma faculdade) que eu tinha". De certa forma, Luíza encontra uma forma de compensar a perda de projetos e tenta usufruir da sensação de ter produzido algo durante a vida. Embora tenha abandonado projetos e mudado constantemente de cidade, envolveu-se nas comunidades onde morou, fazendo amizades. Após a saída do marido do emprego e a mudança em definitivo para Brasília, continuou trabalhando na igreja em que ele trabalhou como pastor titular. Entretanto, com a aposentadoria do esposo, Luíza precisou deixar funções de liderança no departamento de mulheres, e assumiu papel mais periférico na comunidade.

Em alguns momentos durante seu depoimento, demonstrou insatisfação com suas atividades atuais, religiosas e domésticas. Mas percebe aspectos positivos na velhice ao compará-la com as fases anteriores da vida em que precisou mudar-se constantemente. A velhice, de acordo com seu relato, tem Ihe proporcionado a oportunidade de se fixar em um lugar e vivenciar situações novas, como fazer amizades e ter tempo para estar com o marido e a família: "Somos os mais idosos da igreja e respeitam muito a gente", "Uma idade de ficar mais junto com meu marido, com meus netos".

Apesar de ter uma vida inteira dedicada à igreja, o discurso religioso não é muito presente na fala de Luíza, apenas em situações vistas como imutáveis ou inexplicáveis, como a morte do irmão: "Muita tristeza, mas sabemos que foi a vontade de Deus". Ao se deparar com situações difíceis, dispôs-se a enfrentar e a superar dificuldades através do trabalho.

\section{Joaquim: satisfação no cuidado com as pessoas}

Joaquim tem 80 anos, é casado com Luíza e tem 4 filhos. Durante a entrevista, demonstrou bom humor e disposição em contar sua história. Nasceu no interior de Minas Gerais, sendo único filho do primeiro casamento da mãe. Perdeu o pai aos 3 anos e, logo depois, sua mãe casou-se novamente e teve 4 filhos. Estudou com a ajuda financeira dos vizinhos, e, posteriormente, cursou o seminário de teologia com a ajuda de agência missionária americana. Tornou-se missionário e, por 11 
anos, percorreu várias cidades instalando igrejas: "Nessa missão foi difícil. A gente tá no lugar tanto tempo, tem muito trabalho. De repente, era outra mudança! Não era fácil, mas o novo trabalho era bom, tinha novidade. Esses tempos foram bons, me comunicava bem com os americanos". Após aposentar-se, atuou por algum tempo como pastor em igreja brasileira, e atualmente continua ajudando a comunidade através de visitas e palestras. Esse senso de cuidado e envolvimento com as pessoas à sua volta é marcante em Joaquim: "Já tivemos na igreja viúva que não tem nada. Eu fico com dó. São eventos importantes que a gente tem interesse de ajudar". Em seu depoimento, fala com satisfação também acerca dos netos: "Quando chegam lá em casa, é uma confusão. Mas é bom, acham que sou o rei das piadas (risos)".

A velhice é experimentada por Joaquim como tempo de estar quieto, de lembranças, de ter o respeito das pessoas, mas também como tempo de perdas: "(A saúde) Vai indo, pra 80 anos até que tá bem", "A idade foi chegando e a gente vai ficando mole, a memória já tá cansada", "A vantagem é muito respeito na igreja, o povo considera, respeita a idade". A proximidade da morte parece incomodá-lo, e reage ora com humor, ora lançando mão da religiosidade: "(na leitura e assinatura do Termo de Consentimento) Fazendo isso aqui, a gente fica mais novo? (risos)", "(idade) 80, passando um pouquinho, negociei com a morte e ela me deu mais 20 (risos)", "(sobre medo da morte) Não, tudo tá em Cristo, aparece mal, ninguém evita, mas se tá aqui na Terra tem que ser firme".

Apesar de ter sido criado em família muito pobre, orgulha-se das próprias realizações, como ter casa própria, aposentadoria, ter criado os filhos e ter lhes dado estudo: "Sair de uma vida tão difícil e chegar a esse ponto não foi fácil, o que consegui é meu esforço próprio e de muita luta que cheguei à posição que estou, a vida não foi moleza".

\section{Helen e a dificuldade de superar a estagnação}

Durante toda a entrevista, Helen mostrou-se apática, desinteressada e com dificuldades em desenvolver o raciocínio que iniciava. A dificuldade em falar de si mesma, do que não estava satisfatório em sua vida, do significado das perdas sofridas e as formas como as enfrentou esteve presente durante toda a entrevista. Os episódios que se seguem, portanto, não foram obtidos necessariamente nessa ordem.

Helen tem 81 anos, é viúva, nasceu no interior de São Paulo e mora com a filha. É a caçula de uma prole de 18 filhos. Cursou o ensino fundamental em colégio de freiras junto com as irmãs; cursou magistério e trabalhou como professora. Relata que pôde se dedicar aos estudos quando criança, pois o pai sempre sustentou a família. Contou que não se casou muito jovem, e teve 2 filhas. Lecionava na mesma escola onde o marido trabalhava como inspetor de alunos. Por causa disso, precisou deixar as filhas com empregada doméstica enquanto trabalhava.

Trabalhou por cerca de 30 anos. A partir de então, passou a preencher seu tempo com crochê e outras atividades em casa. Não soube dizer há quanto tempo é viúva ou quando foi morar com a filha. Na sua vida atual, transparece a monotonia, pois a filha não a deixa fazer nada: "Eu faço mais é crochê. Assisto televisão. Minha filha não deixa eu fazer as coisas". Assim, Helen ajuda a empregada quando a filha sai para trabalhar, e, no restante do dia, ocupa o tempo com crochê e televisão, mas não se recorda do nome das novelas que assiste. Helen não participa de atividades sociais. É católica, vai à missa aos domingos, mas não relata amizades na comunidade da igreja. Mantém pouco contato com amigos de São Paulo e afirma não ter amigos onde mora. 
Em relação ao casamento, afirma que viveu bem com o marido. Com a viuvez, afirma ter sentido falta do marido, mas não esboça qualquer sentimento. A dificuldade em se lembrar de datas e idades específicas foi marcante no discurso de Helen. Durante todo o depoimento, ocorreram confusões de datas e dificuldade em se localizar temporalmente. Parece que os esquecimentos já fazem parte de sua vida. Afirma que se esquece de fatos do dia a dia: "Agora, depois de velha, é que tô esquecida. A gente acostuma". Em momento algum demonstrou aborrecimento em não se lembrar de datas, de fatos importantes e do nome dos netos e bisnetos. Atribuiu à velhice os problemas de memória.

\section{Joana e a manutenção do senso de cuidado e produtividade}

Joana tem 68 anos de idade, é casada e tem 7 filhos. Nasceu em uma fazenda no interior de seu Estado, e é a quinta filha de uma prole de sete. Vem de uma família de pequenos agricultores e quase não teve acesso à educação. Estudou apenas a cartilha, aprendeu a ler e a escrever, mas precisou abdicar da escola para ajudar o pai na colheita de café e nos afazeres da fazenda. Relata que abandonou os estudos contra a sua vontade. Não ter tido a oportunidade de estudar e não ter retornado aos estudos mais tarde ainda a entristece: "Teve época que fiz matrícula pra começar a estudar, mas não tinha como deixar meus filhos".

Sua infância foi preenchida pelo trabalho, ajuda na roça e papel de cuidadora. Quando a mãe morreu, Joana tinha 8 anos e assumiu as tarefas da casa: "Assumi a casa, toda a responsabilidade. Gostava de fazer as coisas, aprender, aprendia com minha avó". A morte da mãe é marcante para Joana, que se emociona ao relatar os detalhes. Igualmente, o relacionamento com o pai parece ter sido assinalado por cuidado mútuo: "Demorei mais a casar porque parecia que meu pai não queria que eu casasse cedo. Gostava que eu fizesse tudo (se emociona). Era muito apegado comigo..."

Apesar de não ter tido um emprego formal, a produtividade fez parte de sua vida. Como relatado acima, cuidou dos afazeres da casa quando criança. Depois de casada, envolveuse no cuidado dos filhos e em fazer alimentos para vender. Na velhice, confecciona e vende toalhas bordadas.

Outro aspecto importante na vida atual de Joana é o contato com os filhos. Tem o costume de visitar e almoçar com as filhas regularmente, e filhos e netos frequentam sua casa: "A casa não é tão grande, mas tem quintal que os meninos gostam, família grande quando ajunta..." O envolvimento e a participação na comunidade foram presentes na vida de Joana. Desde o início do casamento, participa frequente e ativamente das atividades de sua igreja. Conta que, mesmo a pé e morando longe, ia aos cultos semanais e levava os filhos. Provavelmente, a ausência do marido no dia a dia da dinâmica familiar tenha levado Joana a buscar, na religião, o conforto de que precisava para continuar lutando por dias melhores em sua vida. Atualmente, continua participando de todas as programações da comunidade religiosa.

Joana afirma que sua saúde está boa, mas apresentou dois episódios depressivos nos últimos três anos. Esses episódios foram, segundo a idosa, decorrentes de situações familiares que envolviam problemas de saúde das filhas. Embora reconheça a necessidade de ajuda especializada, apegou-se às crenças religiosas, que parecem lhe proporcionar a certeza de que tudo vai se resolver.

A velhice, para Joana, possui aspectos positivos e negativos, e alegra-se por estar com saúde, apesar de querer mais vigor. A crença religiosa parece auxiliá-la a encarar os desafios e as debilidades da velhice: "Queria ter mais 
vigor, gente mais nova supera as coisas mais fácil. Muitas coisas se passaram e tem que chegar nessa idade, não sou desesperadora com isso. Tenho alegria de ter a força que Deus tem me dado".

\section{Ivonete: superação das perdas corporais}

Ivonete tem 68 anos, é casada e tem 4 filhos, sendo um adotado. Afirma que sua mãe não gostava muito de crianças e a deu para a avó. Não conheceu o pai e nunca se interessou em conhecê-lo. Diz ser resignada com isso, não lamentar e ser grata por ter sido criada pela avó e ter tido a vida que teve. Conta que, durante a infância, precisou auxiliar a avó no sustento da casa. Ajudava a vender hortaliças que cultivavam em casa e doces que a avó fazia. "Tudo que sei, agradeço minha avó, ela era lavadeira de roupa, estudei em escolas públicas e nunca reclamei de nada. Vivi muito bem, minha infância foi muito boa, minha educação também". Fez o curso de técnico em enfermagem e trabalhou em hospitais locais. Devido à escassez de mão de obra especializada na época, assumiu cargos de chefia no hospital psiquiátrico e coordenou a maternidade até se aposentar após 30 de trabalho. Ainda mantém relacionamento de amizade com pessoas que conheceu na época em que trabalhava no hospital. Atualmente, sua participação social envolve atividades de sua comunidade religiosa e do prédio onde reside. Demonstra satisfação em falar sobre essas atividades.

No relacionamento com o marido, com quem é casada há 50 anos, parece haver diálogo e respeito mútuo. Seu marido enfrentou câncer de próstata há algum tempo, e, devido ao tratamento e à cirurgia, tornou-se impotente. Demonstra ter orgulho do esposo: "Criou os filhos muito bem criados, eu sou muito feliz. Graças a Deus". Seu relacionamento com os filhos tem se caracterizado por proximidade maior com o caçula, adotado com poucos meses de vida. Este, apesar de casado, é o mais próximo a Ivonete, e do qual ela demonstra sentir muito orgulho. Esse filho ajuda o pai na oficina mecânica, faz as refeições do dia na casa de Ivonete e é quem lhe dá assistência quando adoece. Há quase 20 anos esse filho foi preso. Narra com detalhes os episódios desse fato e afirma: "Deus me ajudou muito, eu fui com Deus e minha Bíblia e com o advogado, sempre falava: 'o Senhor tá junto comigo'". Como consequência de todas as emoções que sofreu para libertá-lo da prisão, Ivonete desenvolveu angina. Foi internada várias vezes com anemia, necessitando de transfusão de sangue há pouco tempo. A religiosidade é presente em seu depoimento. A crença religiosa lhe proporciona participação em uma comunidade, além de esperança de que os problemas se resolverão.

\section{Isaura e o envolvimento social}

Isaura tem 70 anos, é a quinta dentre 6 filhos, viúva e mãe de um filho adotivo. Nasceu na Bahia, e mudou-se para Goiás quando tinha um ano. Sua infância foi marcada pela pobreza e pela constante luta dos pais e dos irmãos pelo sustento. Com muito esforço, seu pai conseguiu construir uma casa, mas morreu logo depois: "Eu devia tá com uns 12, por aí, foi logo que construiu a casa. Não sei bem o que aconteceu". Suas lembranças da infância são poucas, mas parece não se incomodar com isso. A vivência da pobreza, as dificuldades e as perdas enfrentadas parecem estar bloqueadas ou ser evitadas. Não se lembra de quando se mudaram de cidade, não soube falar como ficou a vida após a morte do pai e nem como foi a morte da mãe quando já estava na maturidade.

Ao relatar a morte do marido, há 11 anos, após complicações do tabagismo e alcoolismo, emocionou-se e chorou. Embora afirme que seu casamento era normal, foi marcado por brigas, pelo alcoolismo e pela agressividade 
física e verbal do marido. Após a sua morte, o envolvimento e a participação social de Isaura aumentaram e parecem trazer-lhe o sentido de pertencimento e a possibilidade de cuidar das pessoas à sua volta. Faz parte de uma comunidade religiosa há muitos anos e participa ativamente das atividades. Afirma que gosta de "visitar porque as pessoas tá precisando de ser ouvida". A satisfação em fazer algo por alguém pode ser percebida em seu relato, o que demonstra a permanência do senso de cuidado na velhice.

A religiosidade é presente ao relatar situações difíceis: "Quando meu marido morreu, eu já tava preparada, Deus tinha me avisado", "Tem hora que passa por isso porque Deus permitiu". As crenças religiosas parecem trazer explicação e aceitação para a morte. Alega receber carinho e respeito das pessoas da igreja e sentir-se amada, mas diz não ter amizades. Mora sozinha e possui boas expectativas futuras: "Vou longe, se Deus quiser. Peço a Ele qualidade de vida".

\section{Lúcio e a falta de objetivos pelos quais lutar}

Lúcio tem 75 anos de idade, é casado e tem 3 filhos. Nasceu e morou na zona rural até a idade adulta. Trabalhou com o trator de seu pai onde moravam e na construção de igreja na região. Sua infância foi assinalada pelo trabalho, por problemas de alcoolismo, pela violência do pai e por nenhum acesso à educação. A morte da mãe foi um dos eventos marcantes na vida de Lúcio: "Ela e minha esposa era muito ligada, morava perto, e ficou muito abatida, e eu também fiquei muito triste, foi uma das coisas mais difícil, aí resolvi mudar pra cá". Ao chegar em Anápolis, trabalhou no beneficiamento de arroz e assumiu funções de pastor em igreja local. Manteve essa jornada dupla por aproximadamente 40 anos.
A aposentadoria é considerada ruim, pois não encontrou outra ocupação que o satisfizesse: "No começo foi bom, mas não foi bom porque a gente fica quieto, não tem o que fazer, sente falta daquilo que a gente ficava trabalhando e hoje não tem mais que ficar lutando". Diante da falta de projetos, Lúcio busca consolo na religião: "Acabou os afazeres, então tem uma esperança, a vida eterna". Outro agravante parece ser a falta de participação social. Atualmente, apenas freqüenta as reuniões de sua igreja sem envolver-se ativamente.

\section{Discussão}

Tendo como base as teorias propostas e as histórias dos idosos, articularemos algumas questões que possam contribuir para a compreensão do envelhecimento. Dentre os participantes, percebeu-se que alguns estão vivenciando uma velhice bem-sucedida. Outros, porém, não conseguiram superar perdas e manter o senso de engajamento e luta por um futuro possível.

Um dos elementos sintônicos que parecem contribuir para que Geraldo, Joaquim e Joana experimentem um envelhecimento com satisfação é a geratividade. Como consequência do desenvolvimento e do fortalecimento desse senso, surge a força psicossocial do cuidado que contribui para o envolvimento vital. Esses três idosos cuidam e se preocupam com as pessoas próximas a eles e com o futuro. Dentre esses três idosos, Geraldo parece exemplificar uma velhice bem adaptada. Enfrentar um trauma aos 73 anos e manter certo grau de satisfação consigo mesmo e com a vida tem sido uma dentre suas muitas conquistas. A psicologia do Lifespan discorre sobre três tipos de envelhecimento: patológico, normal e ótimo. Este último é caracterizado, principalmente, pela ausência de patologias físicas e psíquicas (Baltes \& Baltes, 1990). No entanto, a história de Geraldo demonstra a possibilidade de usufruir de envelhecimento bem-sucedido mesmo na 
presença de sintomas patológicos. Enfrentar traumas e manter a geratividade são desafios que muitos idosos encaram e conseguem, a partir deles, usar estratégias adaptativas e projetar o futuro.

Desenvolver atividades prazerosas que gerem senso de produtividade e criatividade, seja de conhecimento, seja de artesanato ou de cuidado com as pessoas, traz a esses velhos a oportunidade de manterem vínculos de amizade e de se sentirem realmente vivos. $\mathrm{Na}$ velhice, atividades produtivas precisam ser realizadas como estratégia para a conquista e a manutenção de ganhos. Manter o idoso ocupado difere de envolvê-lo em atividades que de fato the proporcionem satisfação. Luíza, esposa de Joaquim, afirmou que "se tirar isso (trabalho) de uma vez, ele morre". A geratividade proporciona a reexperimentação de outras forças psicossociais como competência, iniciativa e esperança, que contribuem para o fortalecimento do envolvimento vital na velhice e para o desenvolvimento da sabedoria e da gerotranscendência. Pesquisa recente demonstra que a geratividade contribui para que o sujeito vivencie bem-estar psicológico, satisfação e qualidade de vida na maturidade e na velhice (An \& Cooney, 2006).

A ausência da geratividade em Helen e Lúcio após a aposentadoria parece ter fortalecido a estagnação. A aposentadoria não é apenas um evento subjetivo, é, sobretudo, um evento social com implicações psicológicas, econômicas e culturais. Muitas vezes contrariando a vontade e a demanda do sujeito, essa conjuntura de fatores o compele a aposentar-se. Infelizmente, nossa sociedade ocidental acaba por "inscrever a pessoa numa perda assimilada ao envelhecimento, dandoIhe uma condição, a aposentadoria" (Messy, 1999, p. 21). As representações sociais inerentes a essa condição trazem, muitas vezes, o estereótipo de estagnação e doença à condição de idoso e aposentado. Assim, além das perdas sucessivas decorrentes da velhice, o idoso precisa enfrentar preconceitos sociais e lutar para conseguir um envolvimento com a vida.

Na velhice, a geratividade necessita ir além do simples cuidado e preocupação com os outros. A grand-generativity (Erikson, Erikson, \& Kivnick, 1986) envolve olhar para fora de si e envolver pessoas à sua volta, mas também olhar para dentro e preocupar-se consigo mesmo. Adicionalmente, engloba a utilização de recursos para promover a própria saúde, mental e física, e culmina no desenvolvimento da sabedoria (Baltes \& Staudinger, 2000; Bluck \& Glück, 2004). Esse elemento está presente em Geraldo, Joaquim, Joana, Isaura e Ivonete, e manifesta-se na preocupação em relação aos filhos, netos e gerações posteriores. Esses sujeitos procuram maximizar ganhos e minimizar perdas, mudam rotinas para melhorar a saúde e buscam acompanhamento médico e formas de superar debilidades físicas. De acordo com Messy (1999), a velhice não é um acesso mandatório para a morte, assim como demência não é, necessariamente, consequência de uma idade avançada.

Lúcio e Helen, entretanto, demonstram não terem podido utilizar, eficientemente, estratégias para selecionar novos objetivos e otimizar recursos disponíveis na superação de perdas. A carência de flexibilidade adaptativa ante mudanças desenvolvimentais e circunstanciais parece contribuir para que a viuvez e a aposentadoria ocasionem estagnação e desinvestimento afetivo do mundo exterior e de si mesmos. Birman (1995) afirma que sintomas depressivos e demenciais podem surgir como manifestações de má adaptação à vida e à velhice. Para Khoury e Günther (2006), mudanças psicossociais ocorridas a partir da meia idade podem acarretar sentimentos negativos e crenças disfuncionais sobre si mesmo e sobre o mundo. Percebe-se que Joaquim se sente inútil e sem sonhos pelos quais lutar, e Helen nem ao menos fala sobre o futuro. 
Os demais sujeitos, Geraldo, Luiza, Joaquim, Joana, Ivonete e Isaura, indicam ter utilizado, no decorrer da vida, estratégias de seleção, otimização e compensação, e, portanto, parecem ter desenvolvido a sabedoria. Conforme Baltes e Staudinger (2004), a sabedoria abrange formas de adaptação que propiciam maximização de ganhos e minimização de perdas. Assim, Ivonete investe em relacionamentos e não permite que limitações físicas a impeçam de realizar atividades que a contentem. Luíza, ainda diante de queixas do passado, encontra satisfação nos filhos e nas atividades religiosas. Joana mantém seu envolvimento com a vida através de pequenos projetos como bordar toalhas. Joaquim conservou a produtividade e o cuidado através da manutenção de atividades da sua profissão e do contato com os netos. Isaura tenta superar um casamento conturbado através da participação social. Geraldo sonha e se empenha para publicar seu livro e construir sites na internet.

A religiosidade esteve presente nos relatos de Luíza, Joaquim, Joana, Ivonete, Isaura e Lúcio, ou seja, tanto em participantes do CMI como da instituição religiosa de Anápolis. A experiência religiosa parece ser elemento comum na velhice. Pesquisas realizadas por Erikson, Erikson e Kivnick (1986), Monteiro (2004) e Yount (2009) constataram que, no fim da vida, a religião pode oferecer consolo e sensação de continuidade existencial. Além disso, pode ser um recurso facilitador na compreensão e na aceitação de perdas. Apesar de esse tema não ser tratado no referencial teórico deste estudo, parece ser um aspecto presente na vida do idoso e digno de pesquisa posterior.

Esses idosos nos ensinam que a vida vai além dos traumas e das dificuldades e precisa ser vivida com intensidade e com a busca por relacionamentos. Py (2004) afirma que o percurso existencial necessita ser um projeto individual que se articula com outros projetos da coletividade. Viver requer compromisso e envolvimento com o contexto relacional. Quando o sujeito se aliena de seu contexto social e não mais se projeta para o futuro, adoece.

Outro fator observado na narrativa dos participantes foi o relato sobre os filhos. As participantes Luíza, Joana e Ivonete mencionaram o cuidado com os filhos e os sacrifícios feitos para criá-los. Com exceção de Ivonete, as outras idosas não seguiram carreira profissional e desenvolveram a geratividade e o cuidado a partir da maternidade. Ivonete fortaleceu esses elementos junto à profissão. Helen, apesar de duas filhas e da carreira, não fala sobre esse tema. Entre os homens, apenas Geraldo falou sobre as filhas. A criação e o cuidado com os filhos parecem receber mais atenção de mulheres (Santos \& Diniz, 2006). Cabe ressaltar que os participantes da pesquisa nasceram na primeira metade do século passado, quando o papel de cuidador era quase exclusivo da mulher. Percebe-se que, com a mudança socio-histórica que vem ocorrendo, esse papel tende a estar mais distribuído entre homens e mulheres. Certamente, os velhos das próximas gerações terão vivenciado o cuidado com os filhos de forma diferente. Investigar os papéis familiares e sociais através do viés do gênero é essencial para melhor compreensão da influência da dinâmica familiar no envelhecimento.

Assim, a partir do que foi discutido, sugestões de intervenções psicossociais podem ser feitas. A assistência a idosos, grupal ou individual, parece trazer resultados muito positivos. Pesquisas realizadas no Centro de Medicina do Idoso do Hospital Universitário da Universidade de Brasília demonstram a eficácia do suporte social e afetivo oferecido através da convivência de idosos em trabalhos grupais. De igual modo, a psicoterapia de indivíduos na maturidade pode resultar na superação de sintomas depressivos e na aceitação dos efeitos do tempo sobre o corpo e o psiquismo (Campos \& Coelho, 2010). Auxiliar idosos-jovens a manter a geratividade e a participação social pode contribuir para o bem-estar na velhice (An \& Cooney, 2006). 


\section{Considerações finais}

Estudar o desenvolvimento humano, assim como o de outras esferas da existência, demanda pensamento holístico. A complexidade da velhice precisa ser avaliada a partir da articulação de fatores além do psicológico, como os aspectos sociais, históricos e antropológicos; destarte, este artigo é um recorte sobre a velhice, e, portanto, demonstrou certas limitações. Devido a dificuldades encontradas para agendar a entrevista com os idosos, haja vista que todos tinham dificuldades em se locomover até o local do encontro, optou-se por realizar apenas uma entrevista. Entretanto, apenas um encontro se mostrou insuficiente para promover o acesso mais detalhado às informações das histórias de cada idoso. Sugere-se, para estudos posteriores, que sejam realizados mais encontros para a entrevista $\mathrm{e}$ que seja repensada a forma de abordagem desses pacientes. Intervalos no meio da sessão psicoterapêutica podem ser um recurso que auxilie o idoso a lidar melhor com seu tempo e com as demandas internas. Normalmente, o velho demonstra dificuldade maior em focalizar a atenção e a concentração, e possui a tendência de cansar-se mais facilmente. São alterações desenvolvimentais que devem ser levadas em consideração, seja na clínica, seja no âmbito da pesquisa. Outro fator que precisa ser ressaltado é a abordagem do paciente dementado ou dotado de certo déficit cognitivo. Como este já apresenta dificuldades em falar de si, além do aumento da dificuldade em concentrar a atenção, o pesquisador precisa redobrar seu cuidado durante a entrevista e buscar formas alternativas de obter as informações desejadas. Perguntar de forma diferente e talvez trazer um componente lúdico ao contato pode auxiliar tanto na obtenção de informações quanto no tratamento psicoterapêutico.

Todavia, observou-se que, mesmo diante de traumas e dificuldades no transcorrer da vida, esta pode ser vivida com intensidade e com a presença de relações sociais saudáveis. Manter essas conquistas e buscar outras colaboram com a arte de viver e envelhecer. A construção de uma boa velhice necessita de ambiente acolhedor que auxilie o idoso no processo de revisão de vida, no enfrentamento de limitações e na elaboração de projetos. De igual modo, aproveitar oportunidades de crescimento e manter vínculos sociais contribuem para um envelhecimento bem-sucedido (Neri, 2005). A arte de envelhecer é, antes de tudo, uma arte de viver e de buscar satisfação em todas as etapas e contextos. Envelhecemos como vivemos, afirma Messy (1999), nem mais, nem menos.

\section{Priscilla Melo Ribeiro de Lima}

Mestre e doutoranda em Psicologia Clínica e Cultura Universidade de Brasília, Brasilia, DF - Brasil.

Professora assistente da Universidade Federal de Goiás, bolsista CAPES

E-mail: primlima@gmail.com

Vera Lúcia Decnop Coelho

Doutora em Psicologia pela Case Western Reserve University, Estados Unidos - EUA.

Pesquisadora associada da Universidade de Brasília

E-mail: vldc@unb.br

Endereço para envio de correspondência:

Rua 235, s/n, Setor Universitário, Goiânia - GO - Brasil. CEP 74605-050

Recebido 12/3/2010, 1a Reformulação 31/5/2010, Aprovado 13/9/2010. 


\section{Referências}

An, J., \& Cooney, T. (2006). Psychological well-being in mid to late life. International Journal of Behavioral Development, $30(5), 410-421$

Baltes, P. (1987). Theoretical propositions of the lifespan developmental psychology: On the dynamics between growth and decline. Developmental Psychology, 23, 611-696.

Baltes, P. (1997). On the incomplete architecture of human ontogeny: Selection, optimization and compensation as foundation of developmental theory. American Psychologist, 52(4), 366-380.

Baltes, P., \& Baltes, M. (1990). Psychological perspectives on successful aging: The model of selective optimization with compensation. In P. Baltes, \& M. Baltes (Orgs.), Successful aging (pp. 1-34). New York: Cambridge University Press.

Baltes, P., \& Staudinger, U. (2000). Wisdom: A metaheuristic (pragmatic) to orchestrate mind and virtue toward excellence. American Psychologist, 55(1), 122-136.

Birman, J. (1995). Futuro de todos nós: temporalidade, memória e terceira idade na psicanállise. In R.Veras (Org.), Terceira idade: um envelhecimento digno para o cidadão do futuro (pp. 29-48). Rio de Janeiro: Relume-Dumará.

Bluck, S., \& Glück, J. (2004). Making things better and learning lessons: Experiencing wisdom across the lifespan. Journal of Personality, 72(3), 543-572.

Bradley, C., \& Marcia, J. (1998). Generativity-stagnation: A five-category model. Journal of Personality, 66(1), 39-64.

Campos, A., \& Coelho, V. (2010). Compartilhando histórias: fatores terapêuticos e mudanças percebidas por idosas participantes de intervenção psicológica grupal. In D. Falcão, \& L. Araújo (Orgs.), Idosos e saúde mental (Vol.1, pp. 165182). Campinas, SP: Papirus.

Erikson, E. (1963). Childhood and society. New York: W.W. Norton \& Company Inc. (Trabalho original publicado em 1950)

Erikson, E. (1998). The life cycle completed: A review. Extended version. New York: W.W. Norton \& Company Inc. (Trabalho original publicado em 1982).

Erikson, E., Erikson, J., \& Kivnick, H. (1986). Vital involvement in old age. New York: W.W. Norton \& Company Inc.

Erikson, J. (1998). The ninth stage. In E. Erikson, The life cycle completed: A review. Extended version (pp.105-114). New York: W.W. Norton \& Company Inc.

Featherman, D., Smith, J. \& Peterson, J. (1990). Successful aging in post-retired society. In P. Baltes, \& M. Baltes (Orgs.), Successful aging (pp.50-93). New York: Cambridge University Press.

Glück, J., Bluck, S., Baron, J., \& McAdams, D. (2005). The wisdom of experience: Autobiographical narratives. International Journal of Behavior Development, 29(3), 197-208.

Goldfarb, D. (2004). Do tempo da memória ao esquecimento da história:estudo psicanalítico das demências. Tese de doutorado, Instituto de Psicologia Universidade de São Paulo, São Paulo.
Khoury, H. \& Günther, I. (2006). Percepção de controle, qualidade de vida e velhice bem-sucedida. In D. Falcão, \& C. Dias (Orgs.), Maturidade e velhice: pesquisas e intervenções psicológicas (Vol. 2, pp. 297-314). São Paulo: Casa do Psicólogo.

Messy, J. (1999). A pessoa idosa não existe (J. S. M. Werneck, Trad.). São Paulo: Aleph.

Minayo, M. (2007). O desafio do conhecimento: pesquisa qualitativa em saúde (10a ed.). São Paulo: HUCITEC.

Monteiro, D. (2004). Espiritualidade e envelhecimento. In L. Py, J. Pacheco, J. Sá, \& S.Goldman (Orgs.), Tempo de envelhecer: percursos e dimensões psicossociais (pp. 159-184). Rio de Janeiro: NAU.

Moura, M. L. S., \& Ferreira, M. C. (2005). Projetos de pesquisa: elaboração, redação e apresentação. Rio de Janeiro: EDUERJ.

Neri, A. (1995). Psicologia do envelhecimento. In A. Neri (Org.), Psicologia do envelhecimeto: temas relacionados na perspectiva do curso de vida (pp.13-40). Campinas, SP: Papirus.

Neri, A. (2005). Apresentação. In A. Neri \& M. Yassuda (Orgs.), Velhice bem-sucedida: aspectos afetivos e cognitivos (pp.7-12). Campinas, SP: Papirus.

Neri, A. (2006a). O legado de Paul Baltes à psicologia do desenvolvimento e do envelhecimento. Temas em Psicologia, 14(1), 17-34

Neri, A. (2006b). Teorias psicológicas do envelhecimento. In E. Freitas, L. Py, F. Cançado, J. Doll, \& M. Gorzoni (Orgs.), Tratado de geriatria e gerontologia (pp. 58-87). Rio de Janeiro: Guanabara Koogan.

Neri, A., \& Yassuda, M. (Eds.).(2004). Velhice bem-sucedida. Campinas, SP: Papirus.

Py, L. (2004). Envelhecimento e subjetividade. In L. Py, J. Pacheco, J. Sá, \& S. Goldman (Orgs.), Tempo de envelhecer: percursos e dimensões psicossociais (pp. 109-136). Rio de Janeiro: NAU.

Santos, C., \& Diniz, G. (2006). Saúde mental de mulheres no climatério: um diálogo entre os estudos feministas e a prática psicológica. In D. Falcão \& C. Dias (Orgs.), Maturidade e velhice: pesquisas e intervenções psicológicas (Vol. 1, pp. 35-56). São Paulo: Casa do Psicólogo.

Tornstam, L. (1999). Transcendence in later life. Generations, 23(4), 10-14

Yount, W. (2009). Transcendence and aging: The secular insights of Erikson and Maslow. Journal of Religion, Spirituality \& Aging, 21, 73-87.

Wadensten, B. (2006). An analysis of psychosocial theories of ageing and their relevance to practical gerontological nursing in Sweden. Scand. J. Caring Sci., 20, 347-354. 